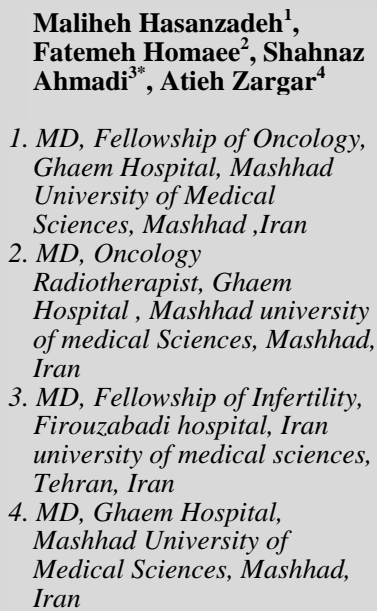

Maliheh Hasanzadeh ${ }^{1}$, Fatemeh Homaee ${ }^{2}$, Shahnaz Ahmadi $^{3^{*}}$, Atieh Zargar ${ }^{4}$

1. MD, Fellowship of Oncology, Ghaem Hospital, Mashhad University of Medical Sciences, Mashhad ,Iran

2. MD, Oncology

Radiotherapist, Ghaem

Hospital , Mashhad university of medical Sciences, Mashhad, Iran

3. $M D$, Fellowship of Infertility, Firouzabadi hospital, Iran university of medical sciences, Tehran, Iran

4. MD, Ghaem Hospital, Mashhad University of Medical Sciences, Mashhad, Iran

*Corresponding Author:

Fellowship of Infertility, Firouzabadi Hospital, Iran University of Medical Sciences , Tehran ,Iran

Tel: 0917-3717981

E-mail: Ahmadishahnaz2005@yahoo.com

\section{Evaluation of Risk Factors of Non Epithelial Ovarian Cancer}

Received: 25 Jun. 2016 ; Accepted: 1 Jul. 2017

\section{Abstract}

Introduction: Non-epithelial ovarian cancers consist of tumors with germ cell and stroma basis and metastatic ovarian tumors. These tumors consist $10 \%$ of ovarian cancers but are more common in our region. In this study our purpose was to have a look at risk factor of these tumors.

Methods: We studied 28 patients with non-epithelial ovarian and 84 control cases were also collected from those who came to genecology's clinic. We evaluated past reproductive history and individual characteristic.

Results: In our study age of marriage, the age of first gestational pregnancy, age of last gestational pregnancy, gravidity, parity, rate of abortion, age of menarche, age of menopause and use of contraception tablets and history of cancer in patient and her family between two group of cases and controls were not significant but body mass index showed statistically significant differences $(p=0.017)$

Conclusion: body mass index was a risk factor for this type of cancer.

Keywords: Non epithelial ovarian cancer, Ovarian Germ cell tumor, Sex cord stromal tumor, Risk factor 


\section{بررسى علل خطر ساز سرطان نان إيتليال تخمدان}

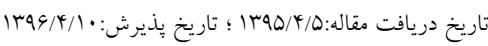

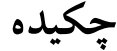

مقدمه: سرطانهاى نان ايتيليال تخمدان شامل تومور زرم سل و طناب جنسى • 1٪ سرطانهاى تخمدان را تشكيل مىدهند. ما در منطقه جغرافيايى ما شيوع بيشترى دارند. اين مطالعه باهدف بررسى فاكتورهاى خطرساز ايجاد اين بيمارى انجام شد.

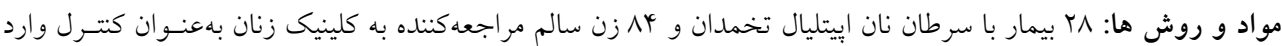
اين مطالعه شدند و فاكتورهايى مانند سابقه بارورى و خصوصيات فردى را موردبررسى قرارداديم. يافته ها: در مطالعه ما سن ازدواج ، سن اولين باردارى ، سن آخرين باردارى ، تعداد باردارىها، تعـداد زايمـانهـا ، تعـداد سقط، سن قاعدگى ، سن يائسخى و استفاده از قرصهاى جلو گيرى از باردارى و سابقه سرطان در خود فرد و خـانو ادهاش در بين دو كروه مورد و كتترل ازنظر آمارى تفاوت معنادارى نداشتند ولى شاخص توده بدنى بين دو گروه تفـاوت آمـارى معنادارى داشت (p) ( نتيجه گيرى : شاخص توده بدنى يك فاكتور خطر براى ايجاد اين نوع سرطان مىباشد. كلمات كليدى: سرطان نان إيتليال تخمدان، تومور زرم سل تخمدان، تومور استروماى طناب جنسى، فاكتور خطرساز

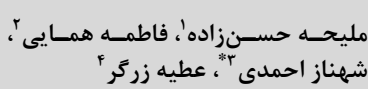

'فلوشيب انكولوزى زنان، بيمارستان قائم،

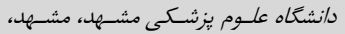
راديوتر/يست /نكولوثى، بيمار ستان قـائم،

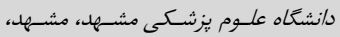

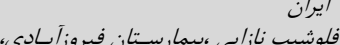

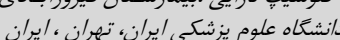

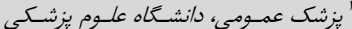

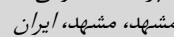

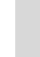


تعداد زايمانها و تعداد سقط و استفاده از قرصهـاى جلـو كيرى از

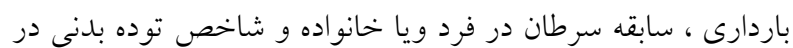

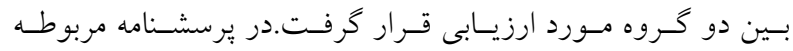

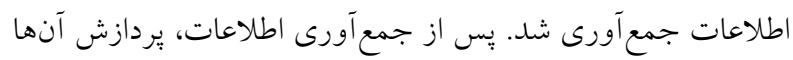

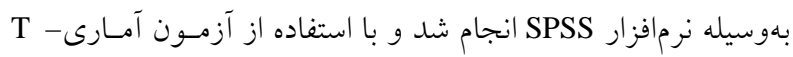
test اطلاعات مورد تجزيهوتحليل قرار كرفتند.

يافته ها

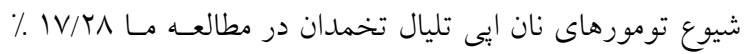

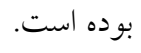

فراوانى انواع تومورهاى نان ابى تليال در افراد موردمطالعه ما در

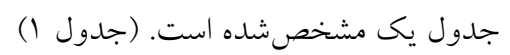

ميانكَين سـنى افـراد در كـروه مسورد كروه كتترل بـ

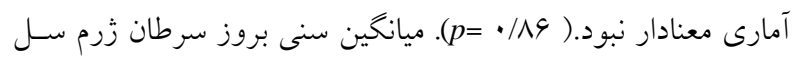

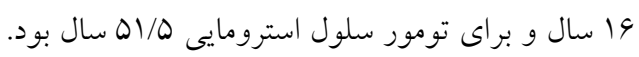

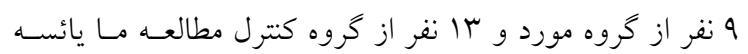

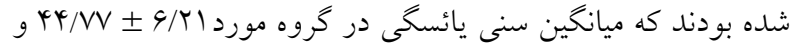

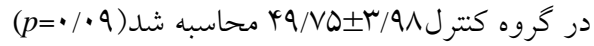

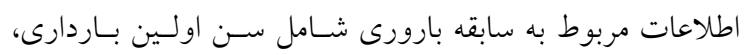

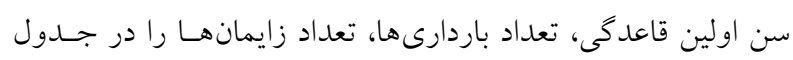

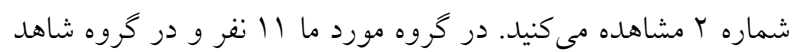

\begin{tabular}{|c|c|c|}
\hline ل درصد & فراوانى & نوع تومور \\
\hline$\% r q / r$ & 11 & كر انولوزا سل تومور \\
\hline$\% r / 0$ & 1 & سرتولى - ليديخ \\
\hline$\% 1 \% / r$ & $r$ & يوك ساك تومور \\
\hline$\% 1 \cdot / \mathrm{V}$ & $r$ & ت ت تراتوم نابالغ \\
\hline$\%$ rQ & v & ديس زرمنيوم \\
\hline$\% r / \Delta$ & 1 & كارسينوم امبريونال تخمدان \\
\hline$\% r / \Delta$ & 1 & تومور زرم سل مخلوط \\
\hline$\% 1 \cdots$ & r^ & كل \\
\hline
\end{tabular}

r r نفر هنوز ازدواجنكرده بودند.( جدول شماره r)
سرطان تخمدان بِنجمين علت عمــهـ مـر كوميرهـاى ناشـى از

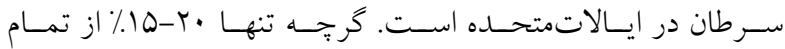
سرطانهاى دستكاه تناسلى زنان از تخمدان ولولههاى رحمى ايجـاد

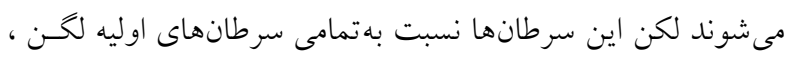

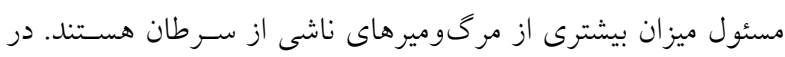

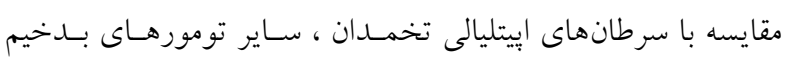
تخمدان ناشايع هستند. بدخيمى هاى غير ايبتليـالى تخمــاندان مسئول

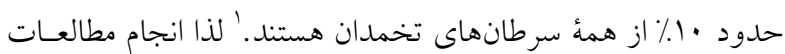
مختلف در اين زمينه همواره موردنياز اسـت. ايسن تومورهـا شـامل

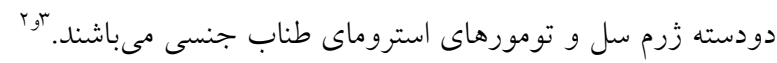

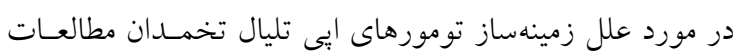

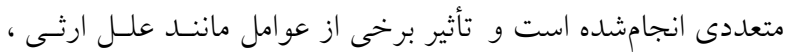
عدم بارورى، مصرف قرصهاى ضدباردارى و.... اثباتشده است.'

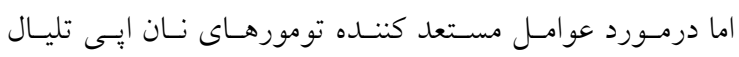
تخمدان اطلاعات كافى در دسترس نمس باشـــ ارتبـاط بـين تعــاد

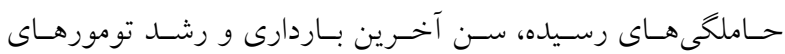

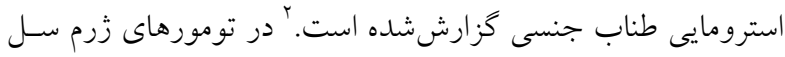
فاكتورهاى بارورى مانند عدم باردارى، سن اولين باردارى، استفاده

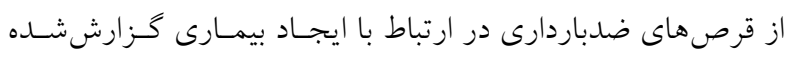
با توجه به شيوع نسبى بالاتر اين سرطانها در ايرانه بران شديم

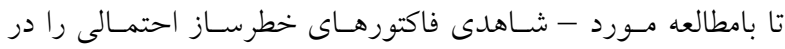
مبتلايان به سرطانهاى نان إيتليال تخمدان مورد ارزيابى قرار دهيم.

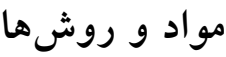

مطالعه ما ، يك مطالعه مورد شاهدى بود كـه در دو بيمارستان

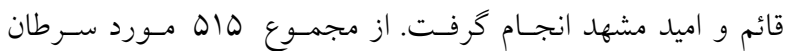
تخمدان كزارششده در دو مركز، 19 بيمـار تومهور نـان إيسى تليـال

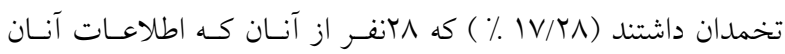

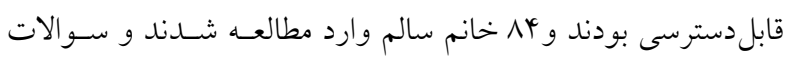

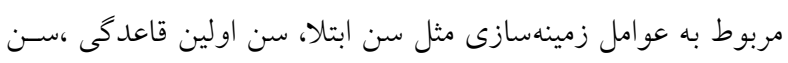

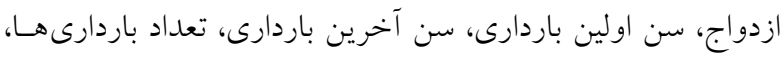


جدول Y: سابقه بارورى دربيماران تحت مطالعه

\begin{tabular}{|c|c|c|c|}
\hline$p$ value & گروه كنترل & گروه بيماران & \\
\hline . THQ & $r / 11 \pm r / r r$ & $9 / \mu r \pm r / \wedge \Delta$ & تعداد باردارىها \\
\hline .194 & $r / \Lambda r \pm r / \mu l$ & $\Delta / \Gamma \Delta \pm r / \varphi q$ & تعداد زايمانها \\
\hline$\cdot / I V Q$ & $\cdot / K Y \pm Y / \cdot q$ & $\cdot .9 \wedge \pm T / T)$ & سابقه سقط \\
\hline$\cdot \pi$ & $|r / 4| \pm Y / 4 \psi$ & $\mid r / N \Psi \pm r / \cdot \varphi$ & سن اولين قاعدگى (سال) \\
\hline$\cdot / \cdot V$ & $\mid \Lambda / T \Delta \pm r$ & $19 / T r \pm r$ & سن ازدواج(سال) \\
\hline$\cdot / T \wedge$ & $19 . / \pm r / \cdot r$ & $\mid N / Y r \pm r / V G$ & سن اولين باردارى (سال) \\
\hline$\cdot / M \Lambda$ & $r \mid / G \Psi \pm r / V$ & $r 1 / q r \pm 0 / 1$ & سن آخرين باردارى(سال) \\
\hline
\end{tabular}

ميزان اين تومورها در منطقه جغرافيايى ما نسبت به آمار جهانى

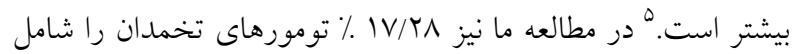
مىشد كه بالاتر از مقادير رفـرانس مسىباشـــ. در ايسن مطالعـه بـين

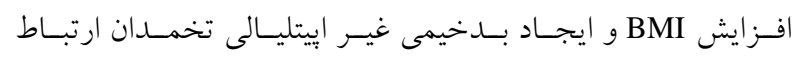

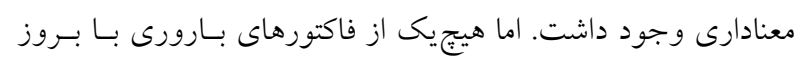

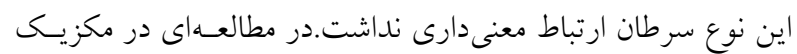
يك ارتباط معكوس بـين تعـداد حساملكى هــاى تـرم، سـن آخـــين

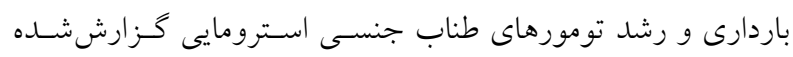

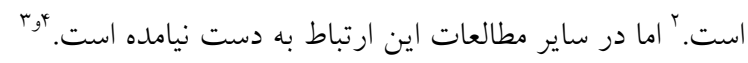

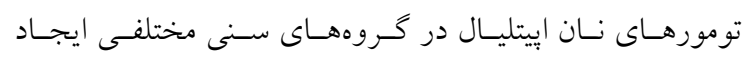

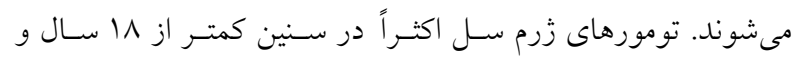
تومورهـاى اسـترومايى تخمــدان در ســين بـس از يائســى اتفــاق مى افتد. در مطالعه Sanchez ميانخين سـنى در تومورهـاى زرم سـل بـ

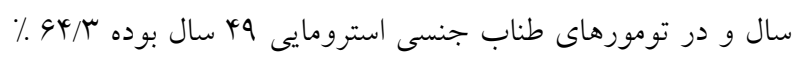

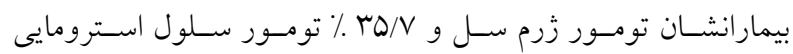

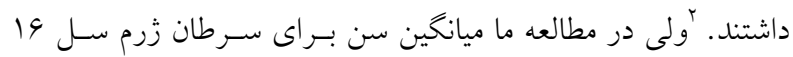

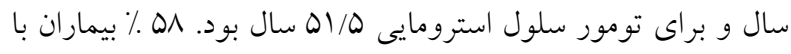

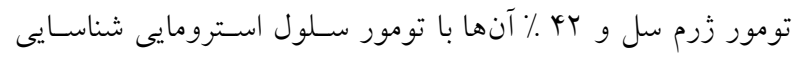
شدند كه بيانكر شيوع بيشتر تومورهاى زرم سل با سن بـايينتـر در منطقه ما است. برخى مطالعات ديس زرمينوم را شايع تـرين تومسور زرم سـل و

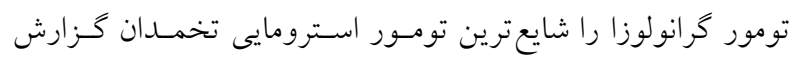
كردماند.

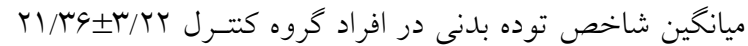

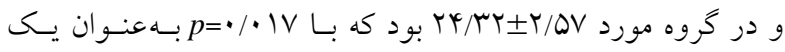

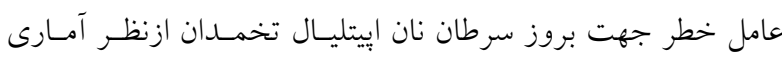
معنادار بود. زايمان زودرس ( كمتر از V هفته ) در ا نفر از خـروه مـورد و

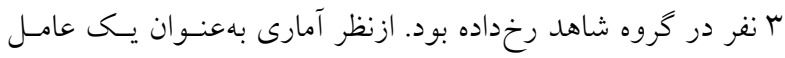

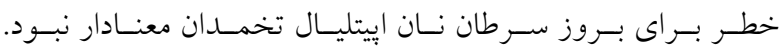
$(p=\cdot / \mu q V)$ نحوه جلو گيرى از باردارى در گروه مـورد و شـاهد مـا از نظـر

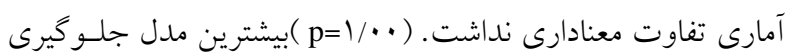
از باردارى استفاده از قرصهاى جلـو گيرى LD ، در هـر دو خـروه

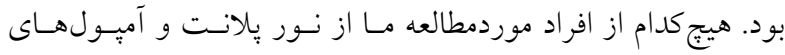

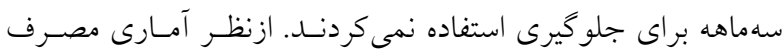
قرصهاى جلو گيرى از باردارى در بين دو گروه مورد معنادار نبود.

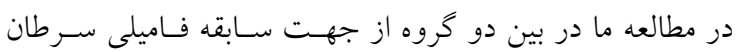

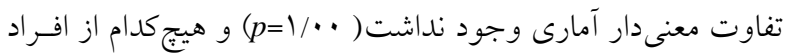
دو خروه،سابقه بدخيمى ديخرى را نداشتند.

بر اساس نتايج اين مطالعه ،شاخص توده بــنى بـهـعنـوان تنهـا فاكتور خطر براى ايجاد اين نوع سرطان مطرح مىباشد.

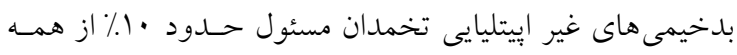

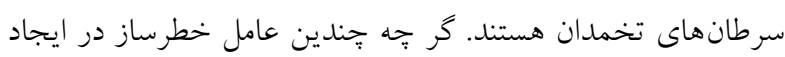
بيمارى مطرحشده است اما علت آن هنوز ناشناخته است. باوبا 
تخمدان كزارششده است.|'^اما در مطالعه ما اين گونه نبود، شـايد دليل اين مسئله بالا بودن بياريته در جامعه ما نسبت به جوامع غربسى لئس

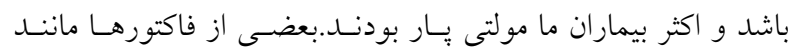

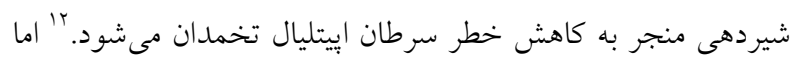
در موردمطالعه ما اين فاكتور، موردبررسى قرار نخرفت.

\section{تتيجه كيرى}

بر اساس نتايج اين مطالعه ،شاخص توده بــنى بـهـعنوان تنهـا

$$
\text { فاكتور خطر براى ايجاد اين نوع سرطان مطرح مىباشد. }
$$

به نظر ميرسد كه با توجه بـهـ تــوع تومورهـاى نـان ايسى تليـال

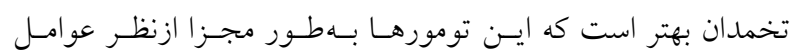

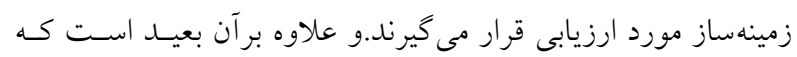

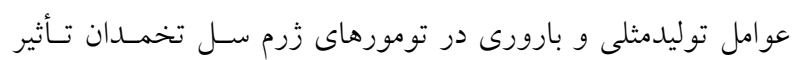
داشته باشند.

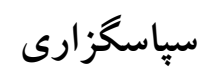

نخارندگان مقاله مراتب تقدير و تشكر خــود را از سـركار خـانم مشتاقى به دليل همكارى در انجام اين تحقيق اعلام مىدارند.

\section{References}

1. Dorigo O, Baker V. Premalignant and malignant disorders of the ovaries and oviducts. In: De cherney AH , Nathan L. Current , obstetric \& Gynecologic, Diagnosis \& treatment. 9th ed. New York: Mc Graw- Hill. 2003: 776-797.

2. Sanchez - Zamarano LM, Salazar -Martinez E, De los Rios PE, Gonzales-lira G,et al. Factors associated with non-epithelial ovarion cancer among Mexican women : a matched Case-Control study. Int J Gynecol cancer. 2003;13(6):756-63.

3. Adami HO, Hsieh CC, Lambe M , Tricopoulos D, Leon D, Person I.et al,Parity, age at first childbirth , and risk of ovarian cancer. Lancet 1994;344(8932):1250-4.

4. Horn-Ross PL, Whittemore AS, Harris R, Itnyre J. Collaborative Ovarian Cancer Group,1992 characteristics relating to ovarian cancer risk. Collaborative analysis of 12 U.S. case control studies.VI. Nonepithelial cancers

$$
\begin{aligned}
& \text { در اين مطالعه ديس زرمينوم شايعترين تومور زرم سل با شيوع }
\end{aligned}
$$

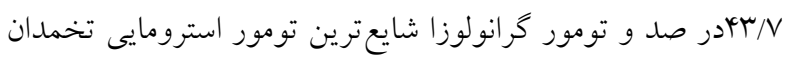

$$
\begin{aligned}
& \text { با شيوع } 91 / 9 \text { درصد بود. } \\
& \text { در مطالعه Sanchez ارتباطى بين سن اولـين بـاردارى بـا بــروز } \\
& \text { يكى از اين تومورها گزارش نشد ، فقط افزايش وزن در طول شـش } \\
& \text { ماه كذشـته بـهـصورت مثبـت بـا هـر دو نسوع تومـور زرم سـل و }
\end{aligned}
$$

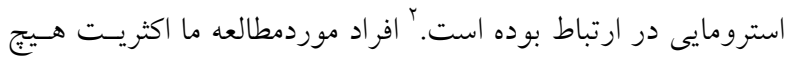

$$
\begin{aligned}
& \text { اطلاع دقيقى از افزايش و يا كاهش وزن خود در سـالهـاى قبـل و }
\end{aligned}
$$

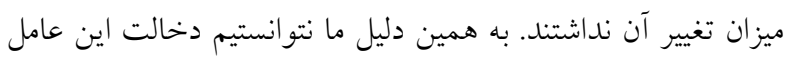

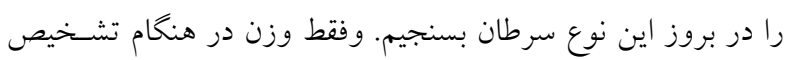

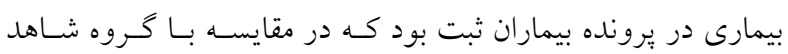

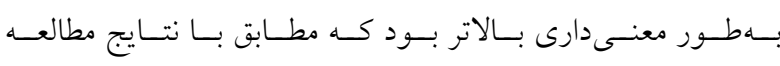

$$
\begin{aligned}
& \text { Bمoyce } \\
& \text { در بعضى از مطالعات كـاهش بـروز ايسن تومورهـا بـا مصـرف }
\end{aligned}
$$

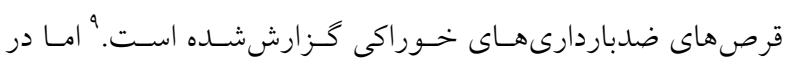

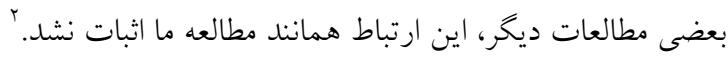

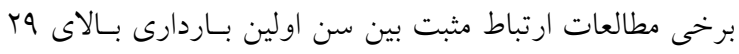

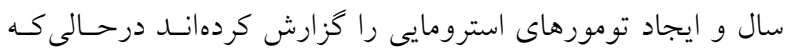

$$
\begin{aligned}
& \text { اين ارتباط براى تومورهـاى زرم سـل وجـود نـدارد. ' امـا در ايسن } \\
& \text { مطالعه اين ارتباط به دست نيامد. } \\
& \text { در بعضى مطالعات افزايش ياريتى بـا كـاهش ريسـى سـرطان }
\end{aligned}
$$

among adults. Epidemiology 1992;3:490-5.

5. Fatemeh Ghaemmagame, Malihe Hasanzadeh. Evaluation of epidemiology of ovarian cancer in Vali-Asr hospital. Iranian J Gynecol Oncol 2008;1(1):5-11.

6. Kanazawa K,Suzuki T,Sakumoto K.Treatment of malignant ovarian germ cell with preservation of fertility: reproductive performance after persistent remission. An J Clin Oncol 2000;23:244-8.

7. Kim YM, Jung MH, Kim KR, Kim JH, Kim YT, Nam $\mathrm{JH}$, Mok JE.Adult granulosa cell tumor of the ovary: 35 cases in a single Korean Institute. Acta Obstet Gynecol Scand. 2006;85(1):112-5.

8. Boyce EA, Costaggini I, Vitonis A, Feltmate C, Muto M, Berkowitz R, Cramer D, Horowitz NS. The epidemiology of ovarian granulosa cell tumors: A case-control study. Gynecologic Oncology 2009; 115:221-225. 
9. Uygun K, Aydiner A, Saip P, Basaran M, Tas F, Kocak Z, et al. Granolosa cell tymor of the overy: reterospective analysis of 45 cases. Am J Clinocol. 2003;26(5): 157-211.

Schneider DT, Janig U, Calaminus G, Gobel U. Harmes D. Ovarian sex cord- stromal tumors: a clinicopathological study of 72 case from the kiel pediatric Tumor Registy. Virchows Arch. 2003;443(4):549-60.Epub 2003
Aug
11. Yang C-Y, Kuo H-W, Chiut H-F. Age at first birth, parity, and risk of death from ovarian cancer in Tiwan a country of low incidence of ovarian cancer. Int $\mathrm{J}$ of Gynecol cancer. 2007;17(1):32-36.

12. Jordan SJ , Siskind V , Green AC, Whiteman DC, Webb PM. Breastfeeding and risk of epithelial ovarian cancer. Cancer Causes Control 2010; 21:109-116. 